\title{
REACTION STRATEGIES FOR SYNTHESIS OF IMIDAZOLE DERIVATIVES: A REVIEW
}

\author{
Sylvia Atanasova-Stamova ${ }^{1}$, Svetlana Georgieva ${ }^{1}$, Maya Georgieva ${ }^{2}$ \\ ${ }^{1}$ Department of Pharmaceutical Sciences and Pharmaceutical Management, \\ Faculty of Pharmacy, Medical University of Varna \\ ${ }^{2}$ Department of Chemistry, Faculty of Pharmacy, Medical University - Sofia
}

\begin{abstract}
The development of a methodical directional synthesis of complex organic molecules with the aim of obtaining the physiologically active substance with selective action takes a central position in modern synthetic organic chemistry. Imidazole derivatives are a key component in great many bioactive compounds of both natural and synthetic origin. Many scientists in the field of pharmaceutical chemistry and pharmacology have been attracted to them in recent years. This is because of the exceptional chemical properties and biological activities that they demonstrate. It is a big challenge for the scientists to modify and synthesize new imidazole derivatives.
\end{abstract}

Keywords: imidazole, synthesis, formamide, microwave

\section{INTRODUCTION}

Imidazole is an organic compound with an empirical formula $\mathrm{C}_{3} \mathrm{H}_{4} \mathrm{~N}_{2}$, shown in Fig. 1. It is a planar five-membered heterocycle with $3 \mathrm{C}$ and $2 \mathrm{~N}$ in positions 1 and 3, which classified it as a "1,3 - diazole". The first name of imidazole was gluoxaline because first synthesis has been made by glyoxal and ammonia. The chemical structure of this heterocycle determinates amphoteric properties, which are a prerequisite for nucleophilic and electrophilic attack. Highly stable in acid, base, thermal, reduction and oxida-

Address for correspondence:

Silvia Atanasova-Stamova

Faculty of Pharmacy

Medical University of Varna

84 Tzar Osvoboditel Blvd

9000 Varna

e-mail:sylviastamova@yahoo.com

Received: September 5, 2018

Accepted: November 26, 2018 tion conditions. Imidazole possesses intramolecular hydrogen bonding. The hydrogen atom can be located in either of the two nitrogen atoms and this is a reason for its existence in two equivalent tautomeric forms. Consisting of a part of the electrons from the protonated nitrogen atom and one from each of the remaining four atoms of the ring - the presence of a sextet of electrons categorizes this compound as aromatic (1).

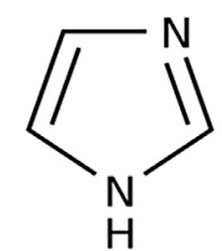

Fig. 1. Chemical structure of imidazole

Imidazole is the basic compound while imidazoles are a class of heterocycles with similar ring structure, but different substituents. Many drugs, such as antimycobacterial drugs, contain an imidazole ring fragment in their structure. Diversified imidazoles 
are biologically and pharmaceutically very important and many of their derivatives possess different activities. For example, they are used as antidiabetic, antihypertensive, and anti-inflammatory drugs.

Recent publications have drawn the attention to the potency and wide relevance of imidazole derivatives. They act as inhibitors of p38 mitogen-activated proteinkinase (2), B-Raf kinase (3), activin receptor-like kinase (ALK5) transforming growth factor b1 (TGF-B1) type 1(4), cyclooxygenase-2 (COX-2) (5) and biosynthesis of interleukin-1 (IL-1) (6). Appropriately substituted imidazoles are extensively used as glucagon receptors(7), modulators of P-glycoprotein (P-gp), CB1 cannabinoid receptor antagonists (8), mediated multidrug resistance (MDR) (9), antibacterial and antitumor agents (10), and also as pesticides (11).

In summary, we can conclude that a large number of imidazoles and imidazole derivatives have been investigated for different biological and pharmacological properties. Therefore, this article aims to review the information for possible synthesis of imidazole derivatives. Imidazole can be synthesized via various methods. Many of these syntheses can also be used for the practical synthesis of different substituted imidazoles and functional groups on the reactants.

\section{REACTION STRATEGIES FOR SYNTHESIS}

In the literature several synthetic methods for 2-imidazoline have been announced starting mainly from aldehydes and ethylenediamine with NBS (12). Some methods include synthesis from carboxylic acids (13), esters (14), orthoesters (15), nitriles (13), hydroxyamides (16) and mono- or disubstituted chlorodicyanovinyl benzene (17).

Imidazole was synthesized for the first time by Heinrich Debus in 1858 although various imidazole derivatives had been discovered as early as the 1840s. Debus synthesized imidazole by using glyoxal and formaldehyde in ammonia as it is shown below on Fig. 2 (18). This synthesis produces a low yield, but it is still used as a major method for the synthesis of C-substituted imidazoles. The reaction products are 2-monosubstituted, and 2, (3,4 homo) trisubstituted imidazoles.

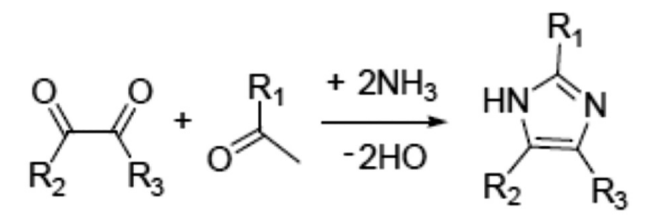

Fig. 2. Synthesis of imidazole by Heinrich Debus

(H. Debus, 1858)

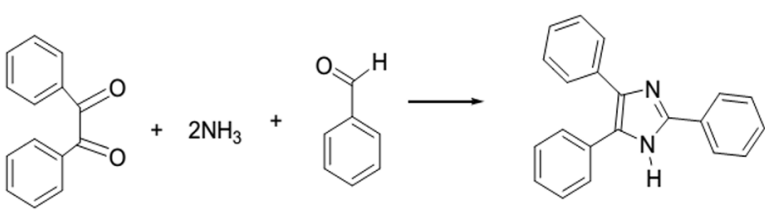

Fig. 3. Synthesis of 2, 4, 5-triphenylimidazole (E. Lunt et al., 1987)

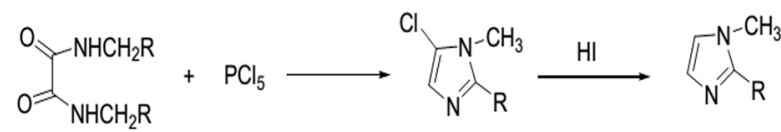

Fig. 4. Synthesis of 1-ethyl-2- methyl imidazole (Na Zhao et al., 2005)

After almost one hundred years Radiszewski communicated that condensation of a benzil and a-keto aldehyde dicarbonyl compound, benzaldehyde or $\alpha$-diketones in the presence of ammonia, yield 2, 4, 5-triphenyl imidazole (19-21). This synthesis is presented in Fig. 3.

Later in 1881 Wallach reported that when N, Ndimethyloxamide is treated with phosphorus pentachloride, a chlorine-containing compound is obtained. Their reduction with hydroiodic acid gives $\mathrm{N}$-methyl imidazole (22-24) presented on Fig. 4.

Other scientists in the new century, Marek et al., synthesized it via a facile four-step reaction sequence starting from inexpensive and easily available $\mathrm{N}$ protected amino acids ( $\mathrm{N}-\mathrm{Cbz}$ amino acids) shown in Fig. 5. They discovered that condensation of formamide acetate with corresponding $\alpha$-bromoketones in liquid ammonia was a useful method for the synthesis of such imidazole derivatives, which are structurally related to histamine (25).

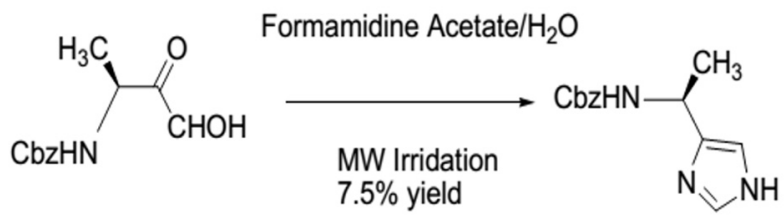

Fig. 5. Synthesis of imidazole derivates structurally related to histamine (Marek et al., 2007) 


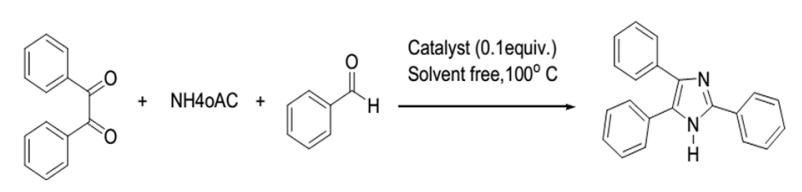

Fig. 6. Synthesis of 2, 4, 5-trisubstituted imidazoles using microwaves (Safari et al. 2010)

In present times, Safari et al. used $\left(\mathrm{NH}_{4}\right)_{6}$. Mo. $7 \mathrm{O}_{2} \cdot 4 \mathrm{H}_{2} \mathrm{O}$ as an effective catalyst for rapid synthesis of 2,4,5-trisubstituted imidazoles, seen in Fig. 6 . The reaction strategy includes condensation of benzil, aryl-aldehydes and ammonium acetate in good yields under solvent-free conditions using microwave irradiation. The microwave-assisted reactions were in accordance with reactions in conventional heating conditions (26).

In the same year, Nalage et al. described an efficient and environmentally friendly strategy for the synthesis of 2, 4, 6-triaryl-1H-imidazole in polyethylene glycol by condensing 3-methoxy-4- hydroxybenzaldehyde and benzil under microwave irradiation. The yield developed was excellent. Polyethylene glycol is reusable, nontoxic, available and inexpensive. The reaction mechanism is shown below in Fig. 7 (27).

In the same period, after one year only, a group of Indian scientists reported a synthesis method

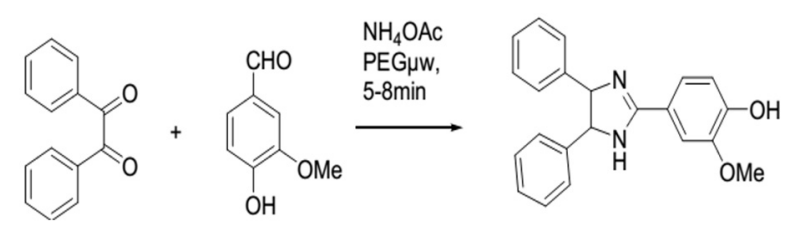

Fig. 7. Synthesis of 2, 4, 6-triaryl-1H-imidazole in polyethylene glycol (Nalage et al 2010)<smiles>O=C(CBr)c1ccccc1</smiles>

(17)

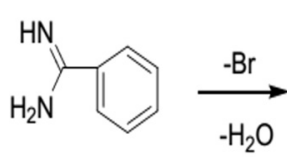

(18)

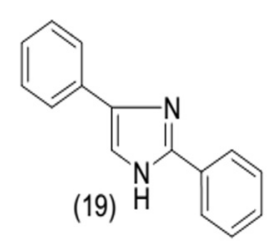<smiles>[R]C(=O)C([R])O</smiles>
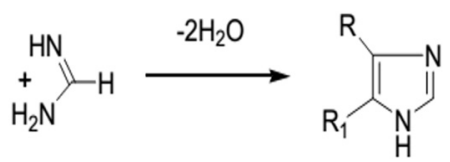

Fig. 8. Synthesis of 2,4- or 2, 5- biphenyl imidazoles (Syed Sultan Qasim et al., 2011) from $\alpha$ - Halo Ketone presented in Fig. 8. This method has been applied successfully for the synthesis of 2, 4- or 2, 5- biphenyl imidazole. Similar is the reaction between acyloin and amidine or alpha halo ketones to yield imidazoles (28).

The preparation of 2-mercaptoimidazoles from $\alpha$-amino ketones or aldehyde and potassium thiocyanate has been used for the synthesis of 2-thiol substituted imidazoles and this method is noted as Markwald synthesis. A variety of the oxidative method can remove the sulfur and give the desired imidazoles shown in Fig. 9 (28).

The mystery of microwave heating has emerged as a valuable alternative in the synthesis of organic compounds. Synthesis of imidazole derivatives by this technique is presented in Fig. 9. Qasim et al. synthesized 2-phenanthroline derivatives. The reaction between dicarbonyl compound and p-substituted benzaldehyde is a type of acid-catalyzed reaction with excellent yields in a neutral ionic liquid, 1-methyl-3-heptylimidazolium tetrafluoroborate [(HeMIM) BF4], under solvent-free and microwaveassisted conditions. This particular reaction highlights all the merits of microwave reactions like environmentally friendly, easy workup and better yield reaction (29).

Many of the steps of synthesis of novel imidazole derivatives are very valuable for the preparation of various intermediates, which can be further modified. Synthesis of imidazole ring derivatives comprises Schiff's bases, 1,3-oxazoline, oxadiazole, thiadiazole and 1,2,4-triazole. The projected compounds were synthesized according to Fig.11 and reaction of 2-(5-methyl-2-nitro-1H-imidazole-1-yl) ethanol

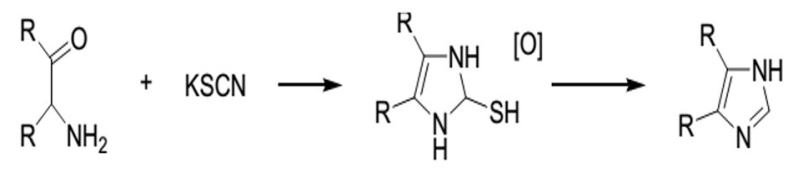

Fig. 9. Synthesis of 2-mercapto imidazoles (Syed Sultan Qasim et al., 2011)

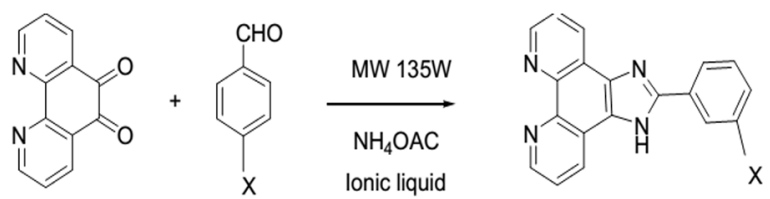

Fig. 10. Synthesis of 2-phenylimidazo [4,5-f] derivates (Syed Sultan Qasim et al., 2011) 


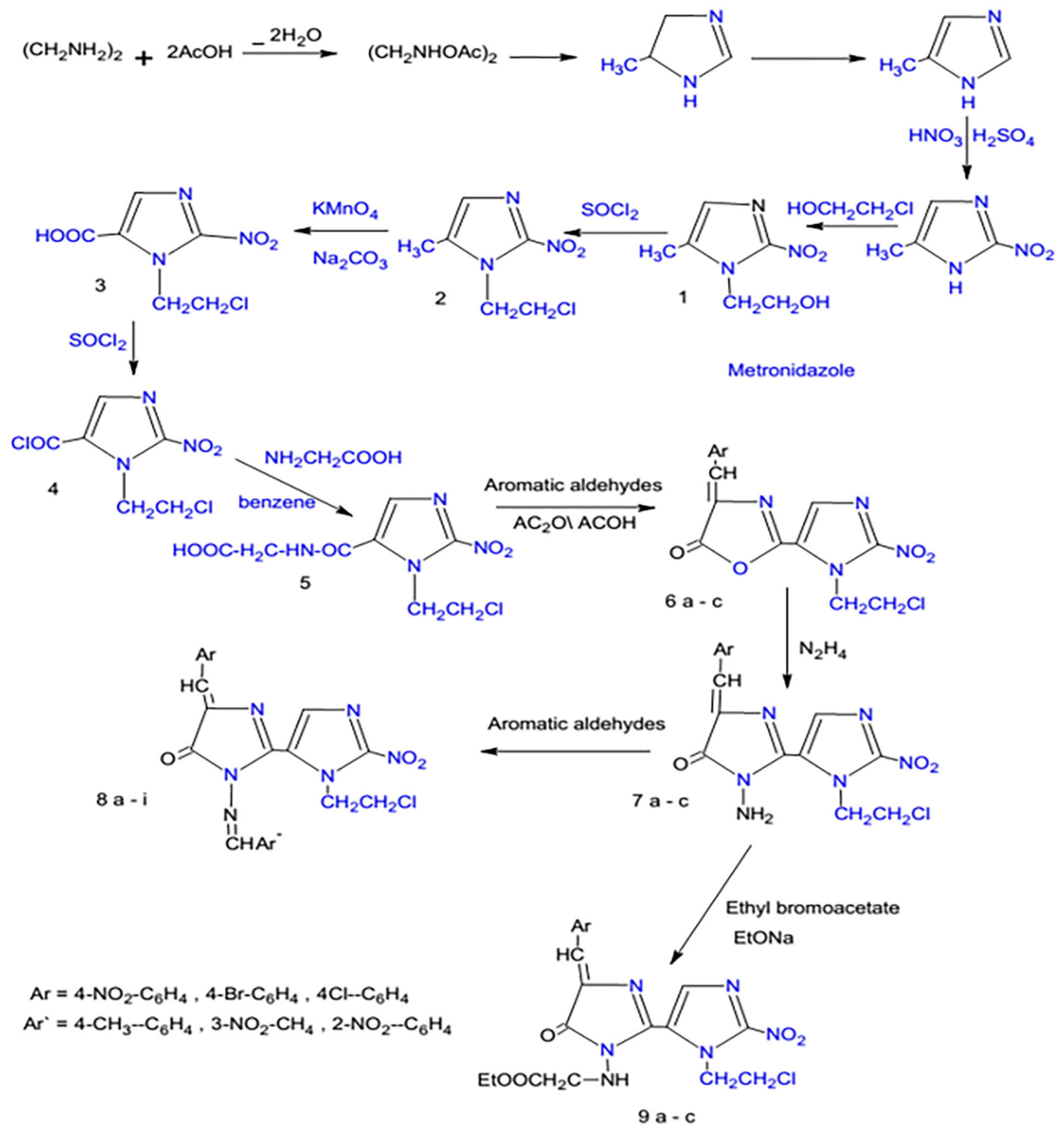

Fig. 11a. The synthesis of compounds $1-9 a-c$ (Abdul Jabar Kh. Atia et al 2009)

(metronidazole, 1) with thionyl chloride provided 1-(2-chloroethyl)-5-methyl-2-nitro-1H-imidazole (30).

The treatment of compounds 9a-c with hydrazine hydrate gave thiosemicarbazide compounds $10 \mathrm{a}-\mathrm{c}$ and compounds 11a-c, accordingly. Acid hydrazides are very useful intermediates used for form- ing some heterocyclic rings such as 1, 3, 4-oxadiazoles, 1, 3, 4-thiadiazoles and 1, 2, 4-triazoles. Another part of the compounds: 3'-(2-chloroethyl)-5-arylidene-3-\{[5-mercapto-1,3,4-oxadiazol-2-yl-methyl]amino -2 '-nitro-3,5-dihydro-3' $\mathrm{H}, 4 \mathrm{H}, 2,4^{\prime}$-biimidazol-4-one and $12 \mathrm{a}-\mathrm{c}$, were synthesized in the pres- 
<smiles>CCOC(=O)CNN1C(=O)C(=[Al])N=C1c1cnc([N+](=O)[O-])n1CC</smiles><smiles>C=C1N=C(c2cnc([N+](=O)[O-])n2CCO)N(CC(N)=O)C1=O</smiles>

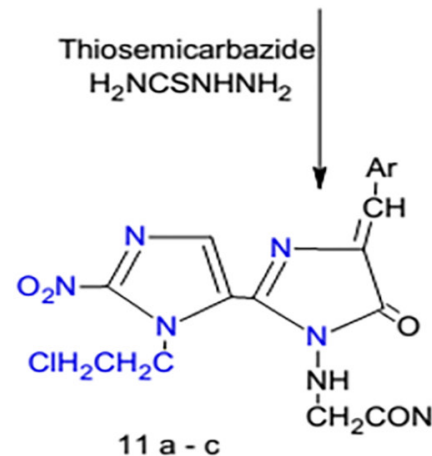<smiles>O[Mg]c1ccccc1</smiles>

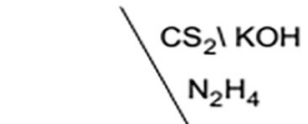
$\mathrm{NH}$<smiles>C=C1N=C(c2cnc([N+](=O)[O-])n2CCCl)N(NCc2nnc(S)o2)C1=O</smiles>

$12 \mathrm{a}-\mathrm{c}$<smiles>CCCN1C(=O)C(=[W])N=C1c1cnc([N+](=O)[O-])n1CC</smiles>

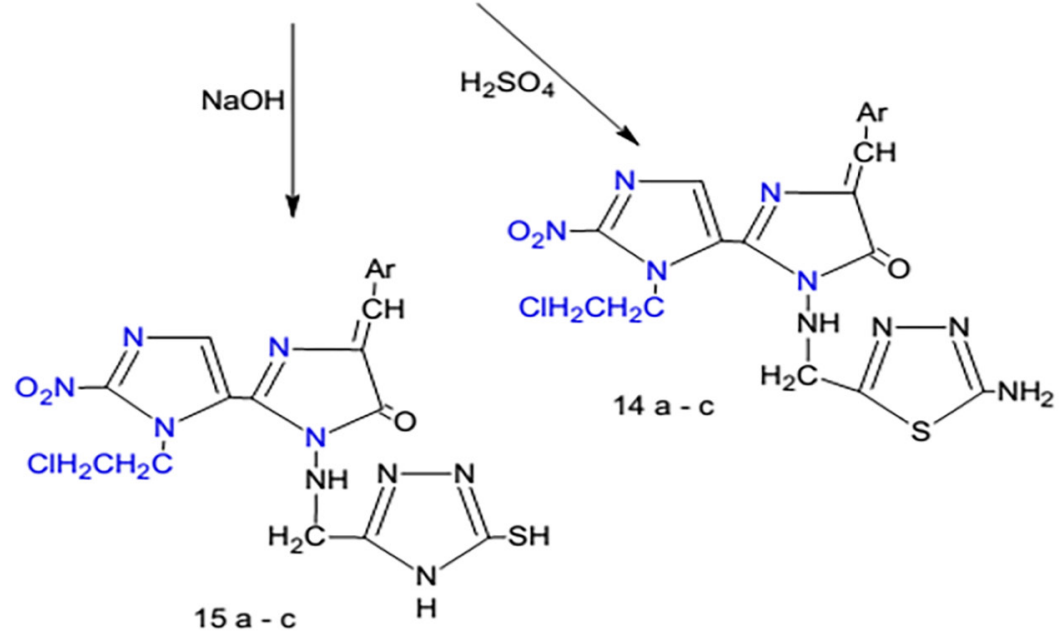

Fig. 11b. The synthesis of compounds 10-15a-c (Abdul Jabar Kh. Atia et al 2009)

ence of potassium hydroxide from the reaction between compounds 10a-c with carbon disulfide (31).

\section{CONCLUSION}

Based on the above-presented literature survey we have underlined the importance of imidazole and its synthetic derivatives. In an attempt to help the medicinal chemists or pharmacists by researches, we have presented new, easy-to-use and environmentally safe synthetic strategies. This review presents further synthetic approaches in applying the most usable strategy for obtaining a huge scope of modified imidazoles bearing different pharmacophores, allowing structures with better effects and low toxicity.

\section{REFERENCES}

1. Romero DH, Heredia VET, García-Barradas O, Lopez ME, Pavón ES. Synthesis of imidazole derivatives and their biological activities. J Chem Biochem. 2014, 2(2):45-83. doi: 10.15640/jcb.v2n2a3.

2. Lee JC, Laydon JT, McDonnell PC, Gallagher TF, Kumar S, Green D, et al. A protein kinase involved in the regulation of inflammatory cytokine biosynthesis. Nature. 1994, 372(6508):739-46. doi: 10.1038/372739a0. 
3. Takle AK, Brown MJ, Davies S, Dean DK, Francis G, Gaiba A, et al. The identification of potent and selective imidazole-based inhibitors of B-Raf kinase. Bioorg Med Chem Lett. 2006;16(2):378-81. doi: 10.1016/j.bmcl.2005.09.072.

4. Khanna IK, Weier RM, Yu Y, Xu XD, Koszyk FJ, Collins PW, et al. 1,2-Diarylpyrroles as potent and selective inhibitors of cyclooxygenase-2-selective, and orally active antiinflammatory agents. J Med Chem.1997; 40(11):1619-33.doi: 10.1021/jm970036a.

5. Lange JHM, Van Stuivenberg HH, Coolen HK, Adolfs TJP, McCreary AC, Keizer HG, et al. Bioisosteric Replacements Of The Pyrazole Moiety Of Rimonabant: Synthesis, biological properties, and molecular modeling investigations of thiazoles, triazoles, and imidazoles as potent and selective CB1 cannabinoid receptor antagonists. J Med Chem. 2005; 48(6):1823-38. doi: 10.1021/jm040843r.

6. Gallagher TF, Fier-Thompson SM, Garigipati RS, Sorenson ME, Smietana JM, Lee D, et al. 2,4,5triarylimidazole inhibitors of IL-1 biosynthesis. Bioorg Med Chem Lett.1995; 5(11):1171-6. doi: 10.1016/0960-894X(95)00189-Z.

7. de Laszlo SE, Hacker C, Li B, Kim D, MacCoss M, Mantlo N, et al. Potent, orally absorbed glucagon receptor antagonists. Bioorg Med Chem Lett. 1999; 9(5):641-6. doi: 10.1016/ S0960-894X(99)00081-5.

8. Eyers PA, Craxton M, Morrice N, Cohen P, Goedert M. Conversion of SB 203580-insensitive MAP kinase family members to drug-sensitive forms by a single amino-acid substitution. Chem Biol. 1998;5(6):321-8.doi: 10.1016/S1074-5521(98)90170-3.

9. Newman MJ, Rodarte JC, Benbatoul KD, Romano SJ, Zhang C, Krane S, et al. Discovery and characterization of OC144-093, a novel inhibitor of p-glycoprotein-mediated multidrug resistance. Cancer Res. 2000; 60(11):2964-72.

10. Antolini M, Bozzoli A, Ghiron C, Kennedy G, Rossi T, Ursini A. Analogues of 4,5-bis(3,5dichlorophenyl)-2-trifluoromethyl-1H-imidazole as potential antibacterial agents. Bioorg Med Chem Lett. 1999;9(7):1023-8. doi: 10.1016/ S0960-894X(99)00112-2.

11. Fujioka H, Murai K, Ohba Y, Hiramastu A, Kita Y. A mild and efficient one-pot synthesis of 2-dihydroimidazoles from aldehydes. Tetrahedron Lett. 2005; 46(13):2197-9. doi: 10.1016/j. tetlet.2005.02.025.
12. (a) Korshin EE, Sabirova LI, Akhadullin AG, Levin YA. Russian Chemistry Bulletin. 1994; 43:431-8. (b) Levesque G, Gressier JC, Proust M. 4,5-Dihydroimidazoles from dithiocarboxylic esters, thiocarboxamides, or nitriles. Synthesis.1981; 12:963-5. doi: 10.1055/s-1981-29659.

13. Vorbriiggen $\mathrm{H}$, Krolikiewicz K. A simple synthesis of $\Delta 2$-oxazolines, $\Delta 2$-oxazines, $\Delta 2$ thiazolines and $\Delta 2$-imidazolines. Tetrahedron Lett. 1981;22(45):4471-4.doi: 10.1016/ S0040-4039(01)93017-5.

14. Hill AJ, Johnston JV. Amidines derived from ethylenediamine. I. Diamidines. J Am Chem Soc. 1954; 76(3): 920-2. doi: 10.1021/ja01632a092.

15. Boland NA, Casey M, Hynes SJ, Matthews JW, Smyth MP. A novel general route for the preparation of enantiopure imidazolines. J Org Chem. 2002; 67(11):3919-22.

16. Shin GI, Kim JH. A New synthetic route to poly(benzimidazole) and the related model reactions to imidazoline and benzimidazole. Bull Korean Chem Soc. 1996; 17(1):29-33. doi: $10.5012 / \mathrm{bkcs}$

17. Davood A, Alipour E, Shafiee A. Efficient synthesis of imidazole derivatives: an important synthon for the preparation of biologically active compounds. Turk J Chem. 2008;32: 389 - 95.

18. Grimmett M. Imidazole and benzimidazole synthesis. $1^{\text {st }}$ edition. Academic Press; 1997.

19. Lunt E, Newton CG, Smith C, Stevens GP, Stevens MF, Straw CG, et al. Antitumor imidazotetrazines. 14. Synthesis and antitumor activity of 6 and 8-substituted imidazo[5,1-d]-1,2,3,5-tetrazinones and 8-substituted pyrazolo[5,1-d]-1,2,3,5-tetrazinones. J Med Chem. 1987;30(2): 357- 66. doi: 10.1021/jm00385a018.

20. Hoffman K. Imidazoles and its derivatives. New York: Interscience; 1953. p. 143-5.

21. Bredereck H, Gompper R, Hayer D, Formamid -Reaktionen, XIII. Imidazole aus $\alpha$-Diketonen. Chem Ber.1959; 92: 338. doi:10.1002/ cber.19590920214.

22. Wallach O, Schuelze E. Ueber Basen der Oxalsäurereihe. Eur J Inorg Chem. 1881; 14:420-3. doi:10.1002/cber.18810140195.

23. 23. Wallach O. Imidazole and its derivatives. Ber. 1876; 184:33-5. 
24. Wallach O. Imidazole and its derivatives. Ber. 1881;14:735.

25. Marek A, Kulhanek J, Ludwig M, Bures F, Sirivennela B, Smarani S, et al. Facile synthesis of optically active imidazole derivatives. Molecules. 2007;12(5):1183-90. doi:10.3390/12051183.

26. Safari J, Khalili SD, Banitaba SH. A novel and an efficient catalyst for one-pot synthesis of 2,4,5-trisubstituted imidazoles by using microwave irradiation under solvent-free conditions. J Chem Sci. 2010; 122(3):437-41. doi:10.1007/ s12039-010-0051-6.

27. Nalage SV, Kalyankar MB, Patil VS, Bhosale SV, Deshmukh SU, Pawar RP. An efficient noncatalytic protocol for the synthesis of trisubstituted imidazole in polyethylene glycol using microwaves. Open Catalysis J. 2010; 3: 58-61. doi:10.1155/2013/512074.
28. Elderfield CR. Heterocyclic compounds.Vol.5. John Wiley \& Sons; 1957. p.744.

29. Kaur N. Synthesis of fused five-membered N,Nheterocycles using microwave irradiation. Synthetic Commun Rev. 2013;45(12):1379-410. doi:10.1080/00 397911.2013.828078.

30. Sarasin J, Wegmann E. Synthèse de l'hétéroxanthine à partir d'un dérivé de l'imidazol. Helv Chim Acta.1924; 7(1):713-9. doi:10.1002/ hlca.19240070187.

31. Nalage SV, Kalyankar MB, Patil VS, Bhosale SV, Deshmukh SU, Pawar RP. An efficient noncatalytic protocol for the synthesis of trisubstituted imidazole in polyethylene glycol using microwaves. Open Catalysis J.2010; 3:58-61. doi: 10.2174/1876214X01003010058. 